\title{
Dual Band BPF Based on Parallel Coupled Lines Loaded by Open Stubs for Ku-Band Satellite Applications
}

\author{
Ahmed S. I. Amar', Osama M. A. Dardeer ${ }^{1,2 *}$, Abdelhaleem A. Zekry' \\ ${ }^{1}$ Electronics and Electrical Communication Engineering Department, Faculty of Engineering, Ain Shams University, Cairo, Egypt \\ ${ }^{2}$ Electronics Research Institute, El-Tahreer St. Dokki, Giza, Egypt \\ Email: Ahmed.S.I.Amar@ieee.org, *osamadardeer@eri.sci.eg, aaazekry@hotmail.com
}

How to cite this paper: Amar, A.S.I., Dardeer, O.M.A. and Zekry, A.A. (2019) Dual Band BPF Based on Parallel Coupled Lines Loaded by Open Stubs for Ku-Band Satellite Applications. Journal of Electromagnetic Analysis and Applications, 11, 148-160.

https://doi.org/10.4236/jemaa.2019.119010

Received: August 1, 2019

Accepted: September 14, 2019

Published: September 17, 2019

Copyright $\odot 2019$ by author(s) and Scientific Research Publishing Inc. This work is licensed under the Creative Commons Attribution International License (CC BY 4.0).

http://creativecommons.org/licenses/by/4.0/

\begin{abstract}
This paper presents a dual band Band Pass Filter (BPF) operating at both the downlink and uplink frequency bands for Ku-band satellite applications. The commonly used frequency band in mobile communications satellites is the $\mathrm{Ku}$-band. These mobile satellite systems help connect remote regions, vehicles, ships, people and aircraft to other parts of the world and/or other mobile or stationary communications units, in addition to serving as navigation systems. The structure of the proposed filter is based on parallel coupled microstrip lines and four sections are used. Tuning the two operational bands can be achieved using two open-circuited stubs at the first and last sections of the parallel coupled microstrip lines. The proposed filter is adjusted to operate at $12.54 \mathrm{GHz}$ and $14.14 \mathrm{GHz}$ for downlink and uplink bands, respectively. The proposed dual band BPF is fabricated, measured, and good agreement is obtained between simulated and measured results.
\end{abstract}

\section{Keywords}

BPF, Single-Band, Wide-Band, Parallel, Coupled Lines, Mobile

Communications, Satellite Transmitters

\section{Introduction}

In modern wireless communications, there is a great need for dual band operation and consequently dual band filters are required. Ku-band satellite transmitters and receivers usually need dual band Band Pass Filter (BPF) at downlink and uplink frequency bands to properly receive intended signals and weed out unwanted interfering ones in order to ensure communication does not get mixed up [1] [2]. 
There are several approaches reported in the literature to design an integrated dual band Band Pass Filter (BPF) [3] [4] [5] [6]. Cascading band stop filter and wideband BPF is a simple idea to generate dual band BPF [3]. Also, open-shorted coupled lines (OSCL) are used to realize dual band BPF [4]. The overall size has been reduced using the folded structure and this contributes to the split of the transmission zero which greatly improves the filter selectivity. A dual-/tri-band $\mathrm{BPF}$ is proposed in [5] which is based on a quintuple-mode resonator (QMR). The bandwidths (BWs) of the passbands are controllable. Recently, open/short circuited stub loaded $\lambda / 4$ resonators are used to generate dual band BPF [6].

Different BPFs have been proposed for Ku-Band applications. A compact BPF for Ku-band applications has been proposed in [7], which consists of five quarter-wavelength $(\lambda / 4)$ stepped-impedance resonators, which are in staggered arrangement. Folded narrow feedlines are used to introduce multiple coupling paths in limited space. A slotted folded substrate integrated waveguide BPF with enhanced bandwidth for $\mathrm{Ku} / \mathrm{K}$ band applications is presented in [8]. It has wide passband with reduced size using folded substrate integrated waveguide (FSIW) technique. The filter is designed by introducing a $\mathrm{C}$ slot and an $\mathrm{E}$ slot in central metallic septum of FSIW respectively. An edge coupled cavity-enclosed Chebyshev BPF at $\mathrm{Ku}$ band is presented in [9]. The orientation of the BPF is kept axially rotated which makes it area efficient. However, all the reported $\mathrm{Ku}$-band $\mathrm{BPFs}$ in the literature provide single operation in the $\mathrm{Ku}$-band range either the downlink band or uplink band or the total Ku-band from 12 to $18 \mathrm{GHz}$.

In this paper, a dual band BPF operating at both the downlink and uplink frequency bands for Ku-band satellite applications is presented. The filter structure is based on parallel coupled lines. The dual band operation is generated by loading the first and last sections with open circuited stubs. Good return loss, compact size, good insertion loss, and high in-between-band isolation can be achieved. The paper is organized as follows. Section II describes the analysis and design of the parallel coupled line BPF. Section III is devoted to results of the proposed filter. The paper is concluded in Section IV.

\section{Filter Design and Analysis}

The design of the presented band pass filter (BPF) is based on parallel coupled line half-wavelength resonator. The order of the parallel coupled line filter is 3 . The designed prototype is fabricated on Rogers RT6010 substrate with dielectric constant $\mathcal{E}_{r}=10.2$, thickness $(h)$ of $1.9 \mathrm{~mm}$, and loss tangent $(\tan \delta=0.0023)$. A three-pole $(n=3)$ filter was selected for our design. The design processes are explained in three steps as follows.

\subsection{Single-Band and Wide-Band Parallel Coupled Line BPF}

Starting from the conventional shape of the microstrip parallel coupled line BPF, a single band BPF can be simply designed. The amplitude ripple in the passband is selected to be $0.5 \mathrm{~dB}$ and the order of the filter is 3 . This means that it is a 
three-pole filter. Designing such coupled line filter is achieved by transforming the cascaded networks by its equivalent RLC circuit using transmission line theory. The following design equations have to be considered [10] [11].

$$
\beta=\ln \left[\operatorname{coth}\left(\frac{G_{r}}{17.37}\right)\right]
$$

where $G_{r}$ is the ripple in the passband.

$$
\begin{gathered}
\gamma=\sinh \left(\frac{\beta}{2 n}\right) \\
a_{k}=\sin \left[\frac{\left(2^{k}-1\right) \pi}{2 n}\right], k=1,2,3, \cdots, n \\
b_{k}=\gamma^{2}+\sin ^{2}\left[\frac{k \pi}{n}\right], k=1,2,3, \cdots, n \\
g_{0}=1, g_{1}=\frac{2 a_{1}}{\gamma}
\end{gathered}
$$

In our case, and at $n=3, \beta=3.548, \gamma=0.62643$. So, $a_{1}=a_{3}=0.5, a_{2}=a_{4}=1$. Then $b_{1}=b_{2}=1.142, b_{3}=1.3924$.

$$
\begin{gathered}
g_{k}=\frac{4 a_{k-1} a_{k}}{b_{k-1} g_{k-1}}, k=2,3,4, \cdots, n \\
g_{m+1}=1 \text { if } n \text { is odd } \\
g_{m+1}=\operatorname{coth}^{2}\left[\frac{\beta}{4}\right] \text { if } n \text { is even }
\end{gathered}
$$

From the mentioned equations, the normalized lowpass Chebyshev filter elements with ripple $0.5 \mathrm{~dB}$ are calculated and the values are as follow:

$$
g_{1}=g_{3}=1.5963, g_{2}=1.0967, g_{4}=1
$$

In addition, the center frequency and the fractional bandwidth are calculated as follow:

$$
w_{0}=\sqrt{w_{1} w_{2}} \text { and fractional } \mathrm{BW}(\Delta)=\left(w_{2}-w_{1}\right) / w_{0}
$$

where $w_{0}=f_{c}, w_{1}=f_{c l}$, and $w_{2}=f_{c h}$.

In order to design the parallel coupled line filter, the following equations are used:

For the 1st coupling structure:

$$
Z_{0} J_{1}=\sqrt{\frac{\pi \Delta}{2 g_{1}}}
$$

For the intermediate structure:

$$
Z_{0} J_{n}=\frac{\pi \Delta}{2 \sqrt{g_{n} g_{n-1}}}
$$

For the final coupling structure: 


$$
Z_{0} J_{n+1}=\sqrt{\frac{\pi \Delta}{2 g_{n} g_{n+1}}}
$$

where $Z_{0}$ is the characteristic impedance, and $J$ is the inverter of admittance.

The characteristic impedance of the parallel coupled lines is divided into odd impedance $\left(Z_{0 o}\right)$ and even impedance $\left(Z_{0 e}\right)$, which can be calculated as:

$$
\begin{aligned}
& \left(Z_{0 o}\right)_{j, j+1}=\frac{1}{Y_{0}}\left[1-\frac{J_{j, j+1}}{Y_{0}}+\left(\frac{J_{j, j+1}}{Y_{0}}\right)^{2}\right] \\
& \left(Z_{0 e}\right)_{j, j+1}=\frac{1}{Y_{0}}\left[1+\frac{J_{j, j+1}}{Y_{0}}+\left(\frac{J_{j, j+1}}{Y_{0}}\right)^{2}\right]
\end{aligned}
$$

According to the Ku-band satellite applications, the frequency band from 11.7 $\mathrm{GHz}$ to $12.2 \mathrm{GHz}$ are assigned for downlink fixed satellite service (FSS) and frequencies from $12.2 \mathrm{GHz}$ to $12.7 \mathrm{GHz}$ are assigned for downlink broadcasting satellite services (BSS). In addition, the frequencies from $14 \mathrm{GHz}$ to $14.5 \mathrm{GHz}$ are assigned for uplink FSS [12] [13].

In order to operate such presented filter at a single band, for example at 12.54 $\mathrm{GHz}$ downlink frequency, the calculated values of the odd and even impedances are given in Table 1 .

The next step is to calculate the parallel coupled line dimensions for the four sections according to the calculated even and odd impedance values. These dimensions have been optimized using the Advanced Design System (ADS) electromagnetic momentum simulator, ver. 2019. The substrate material specifications have been defined correctly to the ADS simulator $\left(\varepsilon_{r}=10.2, h=1.9 \mathrm{~mm}\right.$, and $\tan \delta=0.0023$ ) and the optimized dimensions are given in Table 2.

The ADS structure for these parallel coupled line sections that constitute the downlink BPF is shown in Figure 1. The input/output coupled lines are connected

Table 1. Calculated values of odd and even impedances for downlink.

\begin{tabular}{cccc}
\hline$J$ & $J_{j, j+1} / Y_{0}$ & $\left(Z_{0 e}\right)_{j, j+1}(\Omega)$ & $\left(Z_{00}\right)_{j, j+1}(\Omega)$ \\
\hline 0 & 0.22938 & 64.0997 & 41.1615 \\
1 & 0.12696 & 57.1531 & 44.457 \\
2 & 0.12696 & 57.1531 & 44.457 \\
3 & 0.22938 & 64.0997 & 41.1615
\end{tabular}

Table 2. Optimized dimensions of the coupled line sections for downlink.

\begin{tabular}{cccc}
\hline Stage & $W(\mathrm{~mm})$ & $S(\mathrm{~mm})$ & $L(\mathrm{~mm})$ \\
\hline 1 & 2.07566 & 1.19907 & 2.0803374 \\
2 & 2.28765 & 2.27238 & 2.02678 \\
3 & 2.28765 & 2.27238 & 2.02678 \\
4 & 2.07566 & 1.19907 & 2.0803374
\end{tabular}


with the feed transmission lines, which have $50 \Omega$ impedance. The transmission lines are constructed from the same substrate material (RT/Duroid 6010). Figure 2 depicts the S-parameters in $\mathrm{dB}$ for such BPF. Maximum return loss of 23.8 $\mathrm{dB}$ and insertion loss of $0.7 \mathrm{~dB}$ can be noticed at the downlink resonant frequency of $12.54 \mathrm{GHz}$.

On the same way, the calculated values of the odd and even impedances at 14.14 GHz uplink frequency are given in Table 3.

The optimized dimensions of the four sections of the parallel coupled line are given in Table 4.

The ADS structure for these parallel coupled line sections that constitute the uplink BPF is shown in Figure 3. Figure 4 depicts the $S$-parameters in $\mathrm{dB}$ for such BPF. Maximum return loss of $25.6 \mathrm{~dB}$ and insertion loss of $0.64 \mathrm{~dB}$ can be noticed at the uplink resonant frequency of $14.14 \mathrm{GHz}$.

Following the same procedure, a wide band BPF is proposed with a $3-\mathrm{dB}$ cut off frequencies, $f_{C L}=12.4 \mathrm{GHz}$ and $f_{C H}=14.8 \mathrm{GHz}$. The values of the odd and even impedances for the proposed wide band BPF have been calculated and presented in Table 5.

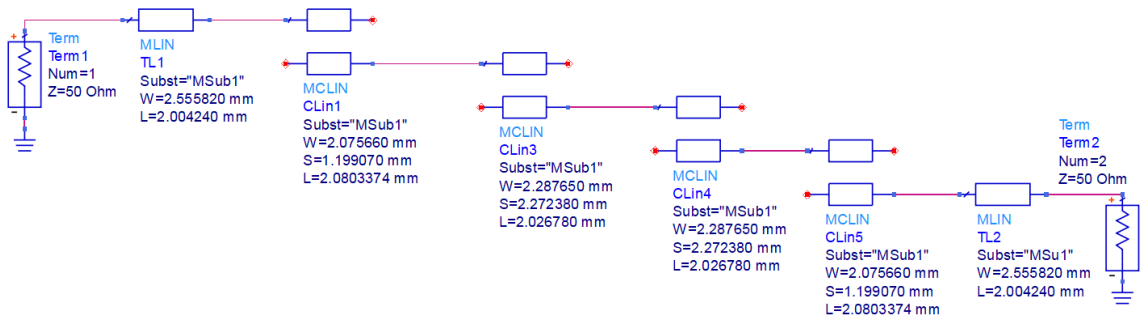

Figure 1. ADS structure of the four sections parallel coupled line BPF for downlink.

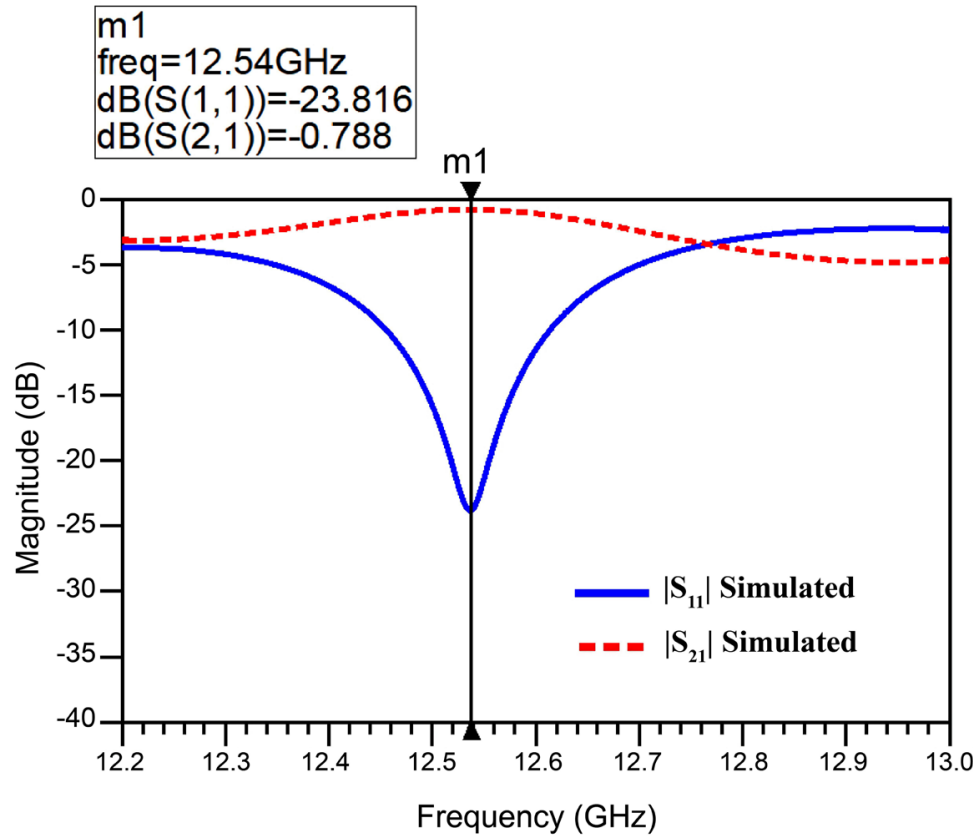

Figure 2. Return loss and insertion loss of the parallel coupled line BPF for downlink. 
Table 3. Calculated values of odd and even impedances for uplink.

\begin{tabular}{cccc}
\hline$J$ & $J_{j, j+1} / Y_{0}$ & $\left(Z_{0 e}\right)_{j, j+1}(\Omega)$ & $\left(Z_{0 o}\right)_{j, j+1}(\Omega)$ \\
\hline 0 & 0.2602 & 66.3801 & 40.381 \\
1 & 0.1623 & 59.492 & 43.172 \\
2 & 0.1623 & 59.492 & 43.172 \\
3 & 0.2602 & 66.3801 & 40.381 \\
\hline
\end{tabular}

Table 4. Optimized dimensions of the coupled line sections for uplink.

\begin{tabular}{cccc}
\hline Stage & $W(\mathrm{~mm})$ & $S(\mathrm{~mm})$ & $L(\mathrm{~mm})$ \\
\hline 1 & 2.10135 & 0.845421 & 1.8149076 \\
2 & 1.46138 & 1.46138 & 1.80468 \\
3 & 1.46138 & 1.46138 & 1.80468 \\
4 & 2.10135 & 0.845421 & 1.8149076 \\
\hline
\end{tabular}

Table 5. Calculated values of odd and even impedances for proposed wide band BPF.

\begin{tabular}{cccc}
\hline$J$ & $J_{j, j+1} / Y_{0}$ & $\left(Z_{0 e}\right)_{j, j+1}(\Omega)$ & $\left(Z_{0 o}\right)_{j, j+1}(\Omega)$ \\
\hline 0 & 0.4672 & 84.2806 & 37.5535 \\
1 & 0.2634 & 66.6405 & 40.2984 \\
2 & 0.2634 & 66.6405 & 40.2984 \\
3 & 0.4672 & 84.2806 & 37.5535 \\
\hline
\end{tabular}

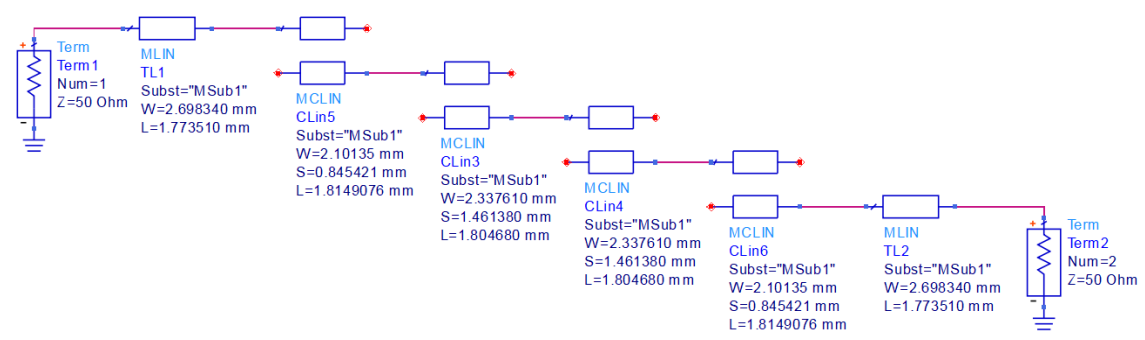

Figure 3. ADS structure of the four sections parallel coupled line BPF for uplink.

The optimized dimensions of the four sections of the proposed wide band parallel coupled line BPF are given in Table 6. The ADS structure for these parallel coupled line sections that constitute the proposed wide band BPF is shown in Figure 5.

A layout for such filter has been generated using ADS for preparing to the fabrication process. The proposed filter layout is shown in Figure 6(a). A prototype of the proposed wide band BPF is illustrated in Figure 6(b). The filter is fabricated on epoxy Rogers 6010 substrate with a dielectric constant of 10.2, thickness (h) of $1.9 \mathrm{~mm}$, and loss tangent of 0.0023 .

Figure 7 depicts both measured and simulated results of the proposed wide band BPF. The measured return loss of about $40 \mathrm{~dB}$ is achieved inside the $\mathrm{ku}$-band and remains better than $10 \mathrm{~dB}$ across the entire band from $12.4 \mathrm{GHz}$ to 


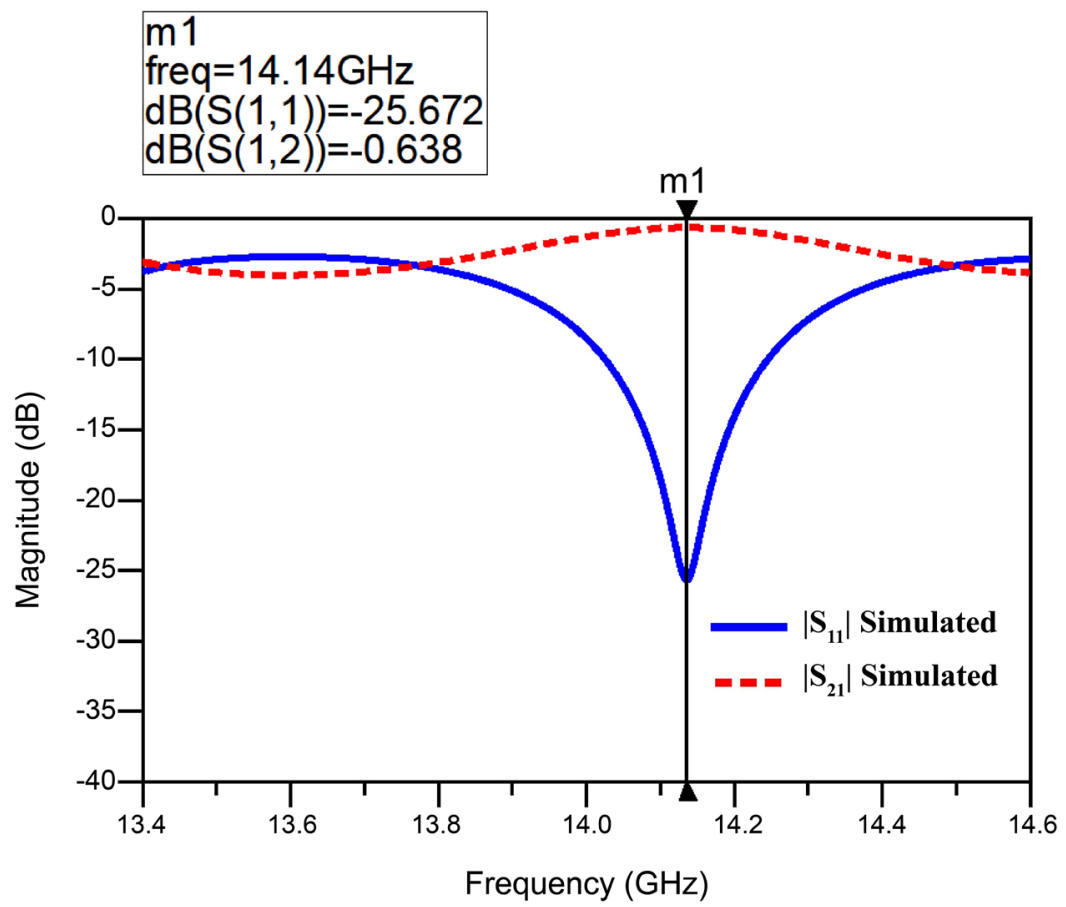

Figure 4. Return loss and insertion loss of the parallel coupled line BPF for uplink.

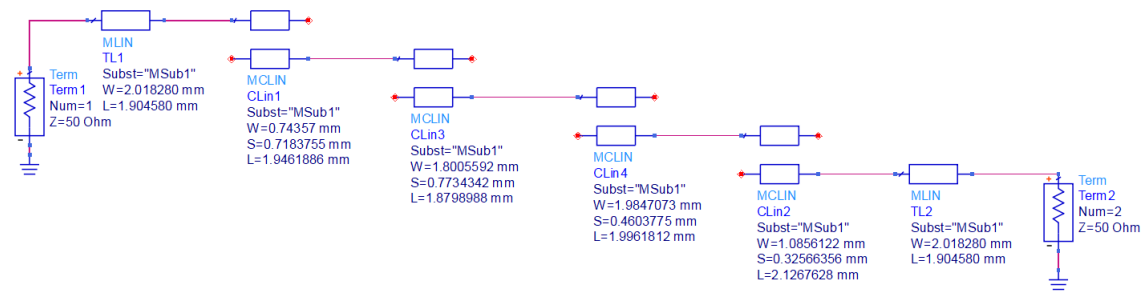

Figure 5. ADS structure of the four sections of the proposed parallel coupled line wide band BPF.

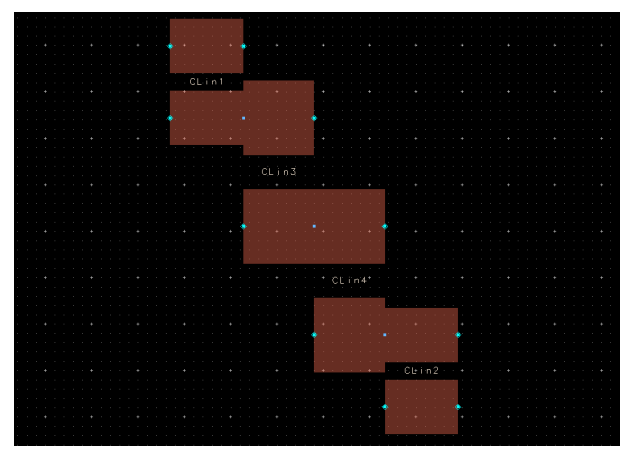

(a)

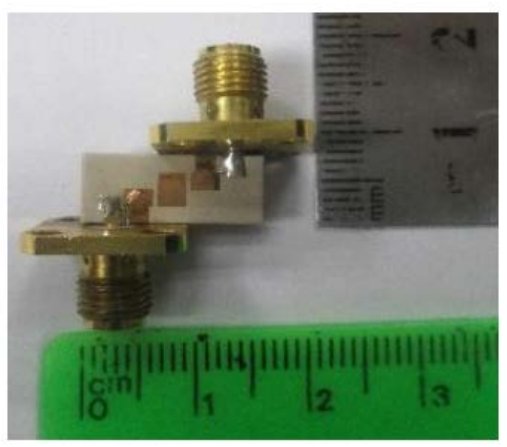

(b)

Figure 6. Proposed wide band parallel coupled line BPF, (a) layout, and (b) photograph of the fabricated filter.

14.8 GHz. The achieved measured insertion loss is $0.71 \mathrm{~dB}$ and $0.78 \mathrm{~dB}$ at 12.5 $\mathrm{GHz}$ and $14.6 \mathrm{GHz}$, respectively, and remains better than $3 \mathrm{~dB}$ across the mentioned band. A good agreement is found between simulated and measured results. 


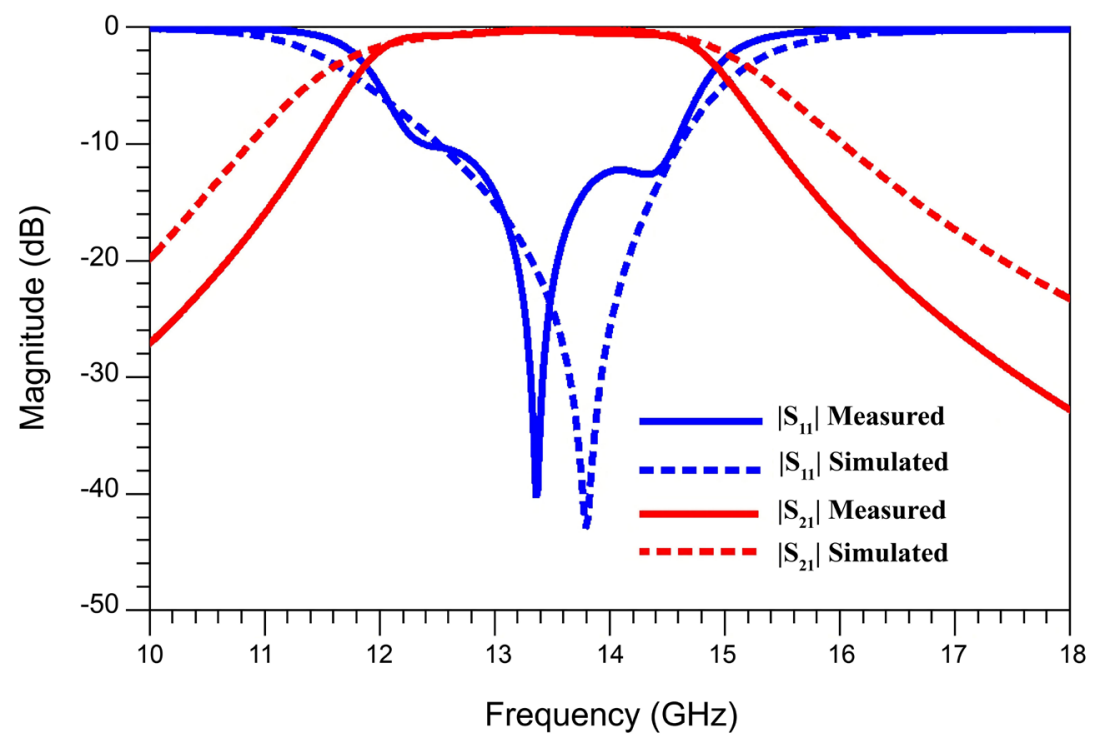

Figure 7. Measured and simulated results of the proposed wide band BPF.

Table 6. Optimized dimensions of the coupled line sections for proposed wide band BPF.

\begin{tabular}{cccc}
\hline Stage & $W(\mathrm{~mm})$ & $S(\mathrm{~mm})$ & $L(\mathrm{~mm})$ \\
\hline 1 & 0.743 & 0.718 & 1.946 \\
2 & 1.8 & 0.773 & 1.879 \\
3 & 1.984 & 0.46 & 1.996 \\
4 & 1.085 & 0.325 & 2.126 \\
\hline
\end{tabular}

The simulated S-parameters are centered at $13.6 \mathrm{GHz}$ while the measure results are shifted slightly and centered at $13.45 \mathrm{GHz}$. Any small difference between simulated and measured results may come from standard manufacture impacts and the copper surface roughness.

\subsection{Tunable Coupled Line BPF Loaded by Capacitor}

In this part, a dual band BPF can be generated by adding lumped capacitors to the coupled line sections. Figure 8 depicts a single section parallel coupled line that contains four ports. The input and output ports are terminated or connected to other cascaded sections while the other two ports are loaded by load impedances. In the case of loading port 2 by a series capacitor connected to ground, the value of this capacitor can be calculated for the dual operational frequencies by the following relation [14]:

$$
Z_{L}=\frac{1}{j w c}, \text { where } w=2 \pi f
$$

The initial values of the lumped capacitors have been calculated using equation (14) and optimized using ADS simulator in order to design a dual band BPF at $12.54 \mathrm{GHz}$ and $14.14 \mathrm{GHz}$ for downlink and uplink frequencies for $\mathrm{Ku}$-band satellite applications. The optimization goals are directed toward improving the 


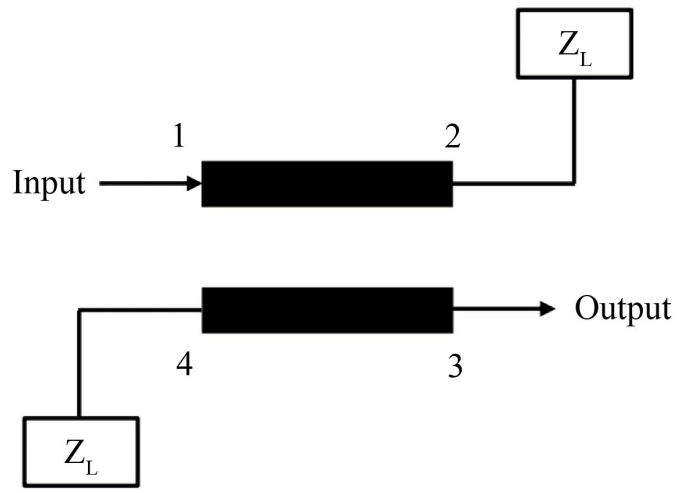

Figure 8. Single section of parallel coupled line.

selectivity and the stop band rejection ratio. The ADS structure for such dual band BPF is shown in Figure 9 and the optimized values for the 2-capacitors are $C_{1}=2.1 \mathrm{pF}$ and $C_{2}=0.19 \mathrm{pF}$. Figure 10 depicts the S-parameters in $\mathrm{dB}$ for such dual band BPF. Maximum return loss of $17.567 \mathrm{~dB}$ and insertion loss of $0.197 \mathrm{~dB}$ can be noticed at the downlink resonant frequency of $12.5 \mathrm{GHz}$. Also, a return loss of $21.58 \mathrm{~dB}$ and insertion loss of $1.526 \mathrm{~dB}$ are achieved at the uplink resonant frequency of $14.17 \mathrm{GHz}$.

\subsection{Proposed Dual Band Coupled Line BPF Loaded by Transmission Line}

In this part, the lumped capacitors are replaced with the open circuited transmission lines. The lumped elements are not preferred due to their parasitics above $1 \mathrm{GHz}$ and the limited available commercial values of these inductors and capacitors. Therefore, a dual band BPF has been proposed using distributed elements without degradation in the performance compared to lumped ones. Figure 11 shows the equivalent to the tuning capacitor which is connected shunt with the coupled line sections. This capacitor is replaced by open-circuited stub in shunt with the coupled sections.

The impedances of the two capacitors $C_{1}$ and $C_{2}$ are calculated and their equivalent $Z_{i n 1}$ and $Z_{i n 2}$ for the two open stubs transmission lines using the normal transmission line impedance equation [15]. The input impedance for an open-circuited transmission line equals $-j Z_{0} \cot (\theta)$. For $\theta=45^{\circ}, Z_{i n}$ equals $-j Z_{0}$. This is equivalent to $\lambda_{g} / 8$ transmission line.

The initial values of the two open stubs are calculated using this procedure, then they are optimized using ADS simulator to achieve acceptable performance compared to the lumped capacitors. The optimization limits are imposed in order to obtain realizable and acceptable dimensions for the open stubs and also the coupled line sections. The ADS structure for such dual band BPF using open stubs instead of lumped capacitors is shown in Figure 12. The frequency responses for that proposed dual band BPF are compared to that obtained by lumped capacitors and there is almost no degradation in the performance as illustrated in Figure 13. 


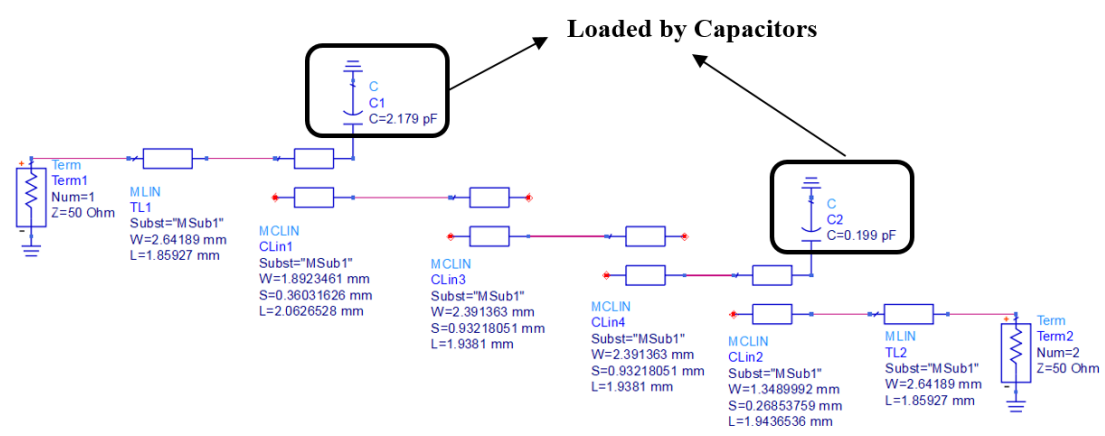

Figure 9. ADS structure of the proposed dual band BPF loaded by lumped capacitors.
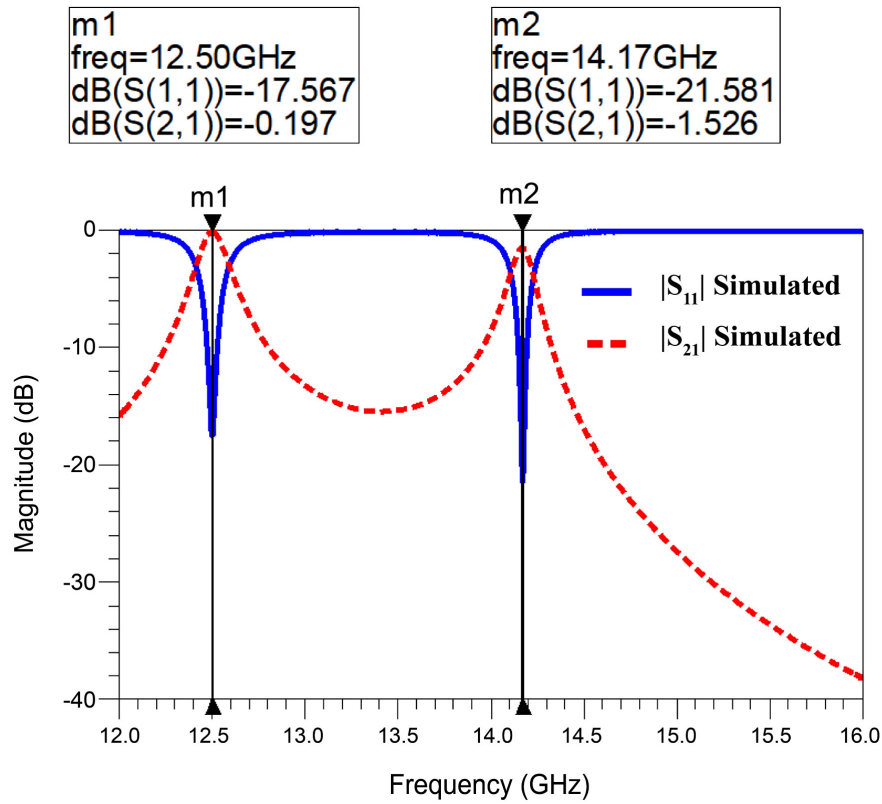

Figure 10. Return loss and insertion loss of the dual band parallel coupled line BPF loaded by lumped capacitors.

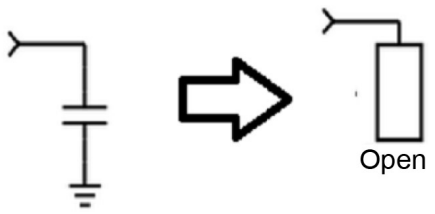

Figure 11. Tuning shunt capacitor equivalence.

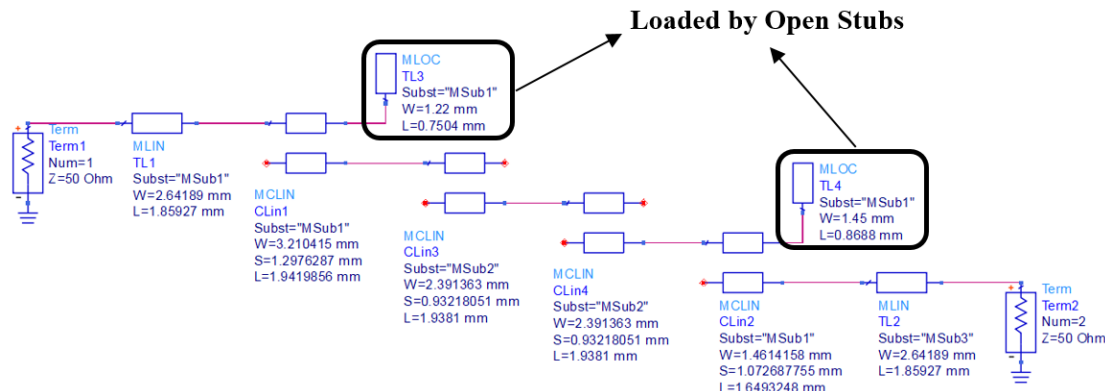

Figure 12. ADS structure of the proposed dual band coupled line BPF loaded by open stubs. 

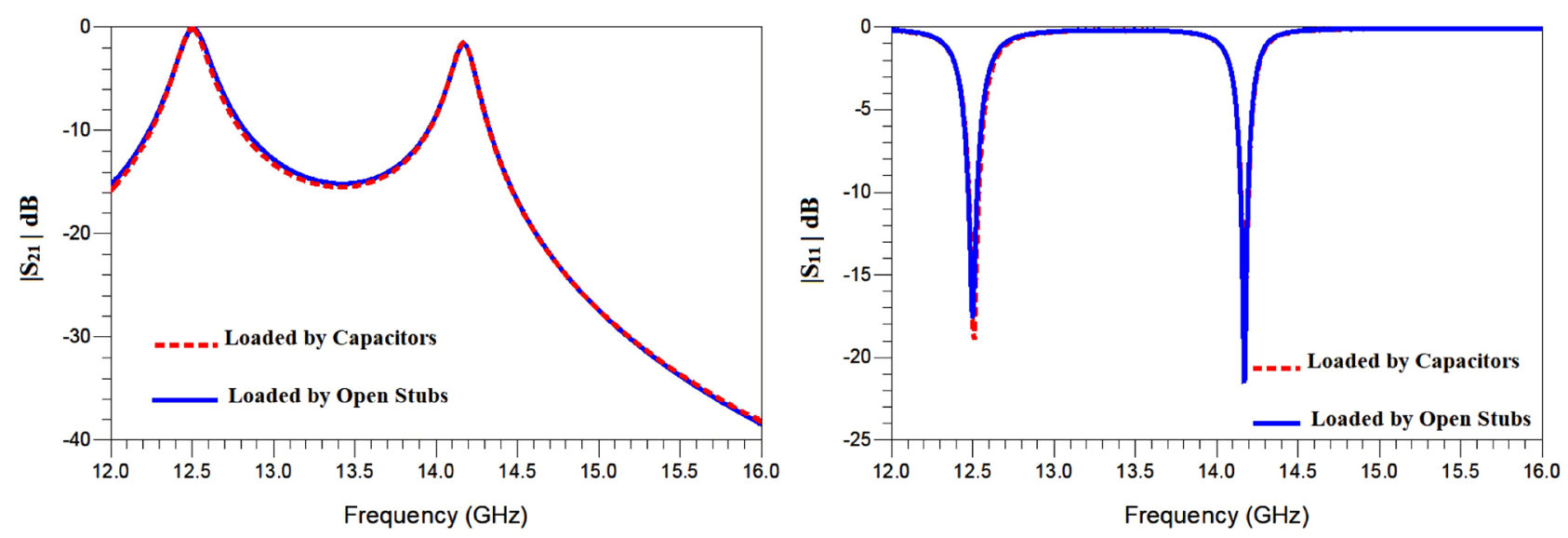

Figure 13. Frequency responses comparison of the proposed dual band BPF in the case of lumped capacitors and open stubs.

\section{Results and Discussion}

A layout for the proposed dual band parallel coupled line BPF loaded by transmission line has been generated using ADS for preparing to the fabrication process. The proposed filter layout is shown in Figure 14(a). A prototype of the proposed dual band BPF is illustrated in Figure 14(b). It can be observed that TL3 and TL4 represent the two open-circuited stubs that can tune the dual operational frequency bands. The filter is fabricated on epoxy Rogers 6010 substrate with a dielectric constant of 10.2, thickness (h) of $1.9 \mathrm{~mm}$, and loss tangent of 0.0023 .

Both measured and simulated results of the proposed dual band BPF are illustrated in Figure 15. A good agreement is found between them. For the downlink operation, the simulation results achieve $90 \mathrm{MHz}$ bandwidth centered at $12.54 \mathrm{GHz}$ and extend from $12.48 \mathrm{GHz}$ to $12.57 \mathrm{GHz}$. The measured results achieve $70 \mathrm{MHz}$ bandwidth centered at $12.53 \mathrm{GHz}$ and extend from $12.49 \mathrm{GHz}$ to $12.56 \mathrm{GHz}$. For the uplink operation, the simulation results achieve $60 \mathrm{MHz}$ bandwidth centered at $14.14 \mathrm{GHz}$ and extend from $14.13 \mathrm{GHz}$ to $14.19 \mathrm{GHz}$. The measured results achieve $50 \mathrm{MHz}$ bandwidth centered at $14.15 \mathrm{GHz}$ and extend from $14.14 \mathrm{GHz}$ to $14.19 \mathrm{GHz}$. Any small difference between simulated and measured results may come from standard manufacture impacts and the copper surface roughness.

\section{Conclusion}

This paper presented a dual band BPF operating at both the downlink and uplink frequency bands for Ku-band satellite applications. The proposed filter was adjusted to operate at $12.54 \mathrm{GHz}$ and $14.14 \mathrm{GHz}$ for downlink and uplink bands, respectively. The proposed dual band BPF was fabricated, measured, and good agreement is obtained between simulated and measured results. The filter dimensions are $25 \times 20 \times 1.9 \mathrm{~mm}^{3}$. The measured results achieved $70 \mathrm{MHz}$ bandwidth centered at $12.53 \mathrm{GHz}(12.49-12.56 \mathrm{GHz})$ for the downlink and $50 \mathrm{MHz}$ bandwidth centered at $14.15 \mathrm{GHz}(14.14-14.19 \mathrm{GHz})$ for the uplink. The proposed 


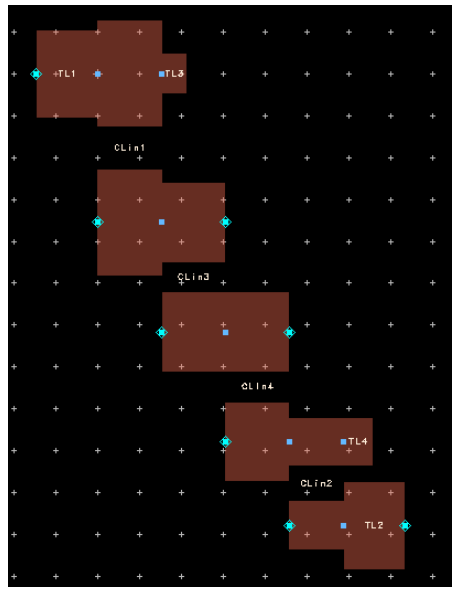

(a)

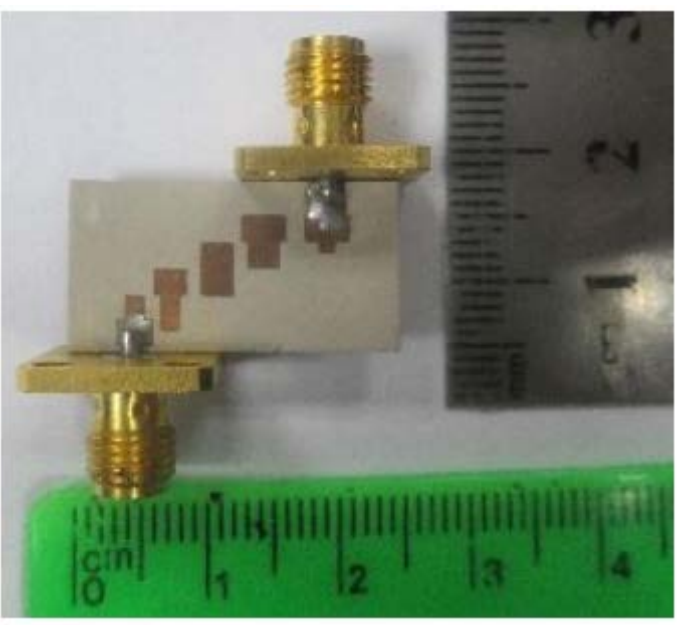

(b)

Figure 14. Proposed dual band parallel coupled line BPF loaded by transmission line, (a) layout, and (b) photograph of the fabricated filter.
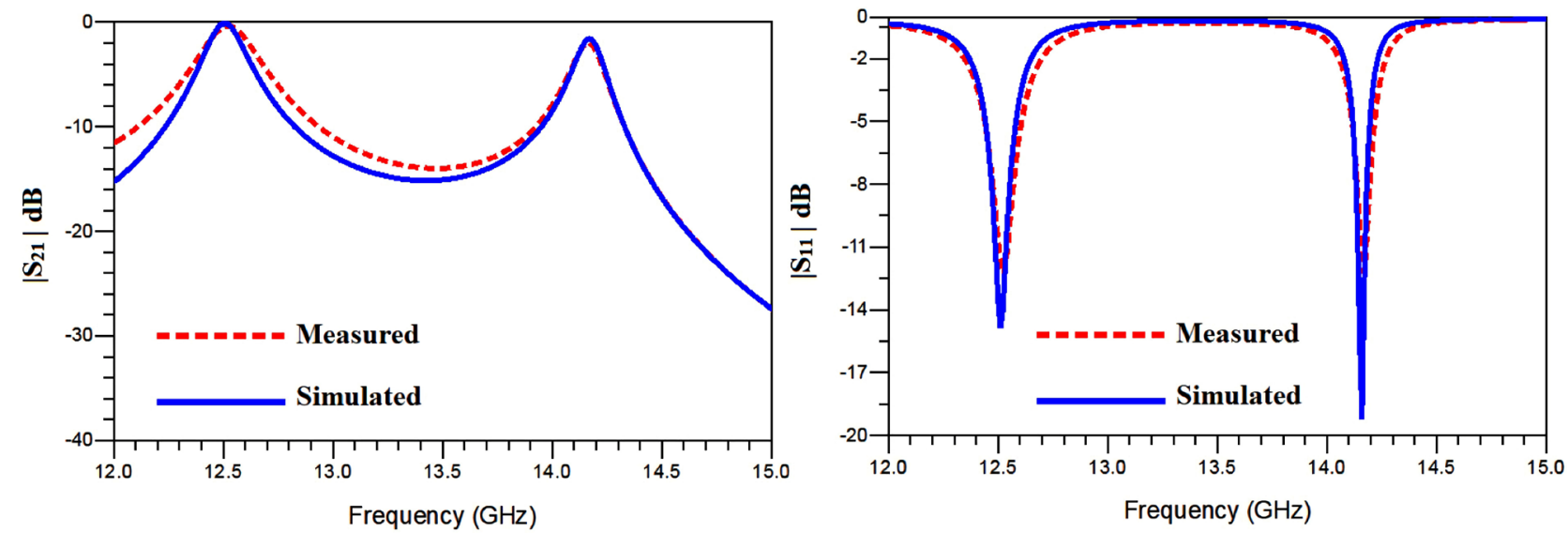

Figure 15. Measured and simulated results of the proposed dual band BPF.

dual band BPF is suitable to be used inside recent microwave satellite receivers used in Ku-band mobile communications satellite transmitters and receivers. In order to complete the RF front end receiver, designing dual band antenna and wideband low noise amplifier can be considered interesting future research studies.

\section{Conflicts of Interest}

The authors declare no conflicts of interest regarding the publication of this paper.

\section{References}

[1] Lee, C.-H. and Laskar, J. (2004) Compact Ku-Band Transmitter Design for Satellite Communication Applications: From System Analysis to Hardware Implementation. Springer Science \& Business Media, Berlin.

[2] KU-Band Bandpass Filter. http://awgrf.com/ku-band-band-pass-filter 
[3] Heng, Y., Guo, X., Cao, B., Wei, B., Zhang, X., Zhang, G. and Song, X. (2013) Compact Superconducting Dual-Band Bandpass Filter by Combining Bandpass and Bandstop Filters. Electronics Letters, 49, 1230-1232. https://doi.org/10.1049/el.2013.2429

[4] Bo, X.-L., Zhang, Y., Li, X., Yang, Y., Tian, Y. and Fan, Y. (2018) A Dual-Wide Band Bandpass Filter Using Open/Shorted Coupled Lines. International Journal of Microwave and Wireless Technologies, 10, 1113-1117. https://doi.org/10.1017/S1759078718001253

[5] Zhang, S.F., Wang, L., Zhao, S., Zhou, J., Wang, Z., Zhang, X., Liang, X., He, M. and Ji, L. (2019) Design of Dual/Tri-Band BPF with Controllable Bandwidth Based on a Quintuple-Mode Resonator. Progress in Electromagnetics Research Letters, 82, 129-137. https://doi.org/10.2528/PIERL18111305

[6] Zhang, Z.C., Chu, Q.X. and Chen, F.C. (2015) Compact Dual-Band Bandpass Filters Using Open-/Short-Circuited Stub-Loaded $\lambda / 4$ Resonators. IEEE Microwave and Wireless Components Letters, 25, 657-659. https://doi.org/10.1109/LMWC.2015.2463216

[7] Xu, J., Hong, W., Zhang, H. and Tang, H. (2017) Compact Bandpass Filter with Multiple Coupling Paths in Limited Space for Ku-Band Application. IEEE Microwave and Wireless Components Letters, 27, 251-253. https://doi.org/10.1109/LMWC.2017.2661970

[8] Muchhal, N., Chakraborty, A., Vishwakarma, M. and Srivastava, S. (2018) Slotted Folded Substrate Integrated Waveguide Band Pass Filter with Enhanced Bandwidth for $\mathrm{Ku} / \mathrm{K}$ Band Applications. Progress in Electromagnetics Research M, 70, 51-60.

[9] Khan, Z.B., Huiling, Z., Mehdi, G. and Madni, M.Y. (2015) Design and Measurement of Cavity Enclosed Microstrip Edge-Coupled Bandpass Filter at Ku Band. IEEE International Conference on Signal Processing, Communications and Computing, Ningbo, 19-22 September 2015, 1-4. https://ieeexplore.ieee.org/document/7338919 https://doi.org/10.1109/ICSPCC.2015.7338919

[10] Hong, J.S. and Lancaster, M.J. (2004) Microstrip Filters for RF/Microwave Application. Wiley, Hoboken.

[11] Marimuthu, J., Abbosh, A.M. and Henin, B. (2013) Planar Microstrip Bandpass Filter with Wide Dual Bands Using Parallel-Coupled Lines and Stepped Impedance Resonators. Progress in Electromagnetics Research C, 35, 49-61. https://doi.org/10.2528/PIERC12110402

[12] Satellite Frequency Bands. https://www.esa.int/Our_Activities/Telecommunications_Integrated_Applications/ Satellite_frequency_bands

[13] Satellite Frequency Bands of Operation. http://www.rfwireless-world.com/Tutorials/satellite-frequency-bands.html

[14] Kaveri, S.V. (2008) Design of Tunable Edge-Coupled Microstrip Bandpass Filters. M.S. Thesis, Utah State University, Logan.

[15] Pozar, D.M. (2011) Microwave Engineering. 4th Edition, John Wiley \& Sons, Hoboken. 